\title{
AGE-RELATED DEFICITS IN THE FREQUENCY OF GAZE RESPONSES TO THE MIRRORS AND BLIND-SPOT DURING LANE CHANGE MANEUVERS OF VARIOUS COMPLEXITY
}

\author{
Martin Lavallière, ${ }^{1}$ Nathan Ngân, ${ }^{1}$ Mathieu Tremblay, ${ }^{1}$ Denis Laurendeau, ${ }^{2}$ \\ Charles T. Scialfa, ${ }^{3}$ Martin Simoneau, ${ }^{1}$ and Normand Teasdale ${ }^{1}$ \\ ${ }^{1}$ Division de kinésiologie \\ Faculté de médecine \\ ${ }^{2}$ Génie électrique et génie informatique \\ Université Laval, Québec \\ ${ }^{3}$ Department of Psychology \\ University of Calgary, Calgary \\ Canada \\ E-mail: normand.teasdale@kin.msp.ulaval.ca
}

\begin{abstract}
Summary: Lane changing is a complex driving maneuver that could challenge elderly drivers. The aim of this study was to evaluate eye glances of young and elderly active drivers when engaging lane change maneuvers. Twelve young (aged 21-31 years) and eleven older (aged 65-75 years) active drivers drove through a continuous simulated environment (STISIM, v2.0). The scenario included 16 events where the driver needed to glance at three important regions of interest (ROI): 1) the rear-view mirror, 2) the left-side mirror, and 3) the left blind spot to ensure secure lane change. The lane change maneuvers were necessary 1) to avoid a static object that was partially or completely blocking the lane or 2) for overtaking a slower moving vehicle. Compared with younger drivers, older drivers showed a reduced frequency of glances towards the left-side mirror and the blind spot. Also, while the older drivers showed a constant frequency of glances across the two types of driving maneuvers (i.e., avoiding a static object and overtaking a slower vehicle), the younger drivers generally showed a higher frequency of glances and this frequency increased when overtaking a slower vehicle. A better knowledge of the elderly drivers' behavior could enable researchers to identify at-risk behaviors and to retrain older drivers to adopt safer behaviors.
\end{abstract}

\section{INTRODUCTION}

Driving is a complex task and more difficult driving contexts such as negotiating intersections and overtaking maneuvers often challenge older drivers (Cooper, 1990; Keskinen, Ota, \& Katila, 1998; Owsley et al., 1998). Often, head and eye movements are necessary to bring the image of surrounding objects (most often neighbouring vehicles) on the fovea (Land, 2006). For instance, before changing lanes for overtaking a slower vehicle the driver needs to check the rear-view and left-side mirrors and the left blind spot, using appropriate eye-head movements. These perceptual-motor processes are continual and make up the basis for complex decision making yielding to secure lane changing. Perhaps one of the most widely cited studies on eye fixation patterns is that of Mourant and Rockwell (1972). They reported that, compared with more experienced drivers, novice drivers sampled their rear-view and left-side mirrors less often and 
concentrated their visual search on a smaller area that was closer to the vehicle. Underwood and colleagues (Crundall \& Underwood, 1998; Underwood, Chapman, Brocklehurst, Underwood, \& Crundall, 2003; Underwood, Crundall, \& Chapman, 2002) and others (Falkmer \& Gregersen, 2005) recently added to this work with a series of studies comparing novice and more experienced drivers. Without going into the details of these experiments, it can be said that experienced drivers selected visual search strategies according to the complexity of the driving context and showed a greater variety of scanning behaviours than novice drivers. There are also a series of studies looking at the specific eye-head movements before a lane change. For instance, Robinson et al. (1972) reported that the first search is towards the left-side mirror in $70-80 \%$ of lane changes, and that the number of glances increases with increased traffic density. More recently, Wierwille and collaborators conducted an extensive analysis of on-the-road glances of experienced drivers during the 3-s period preceding lane changes (Olsen, Lee, \& Wierwille, $2002 ; 2005)$. They reported glance durations of $2.4 \mathrm{~s}$ with $46 \%$ of the left-lane changes having a glance to the rear-view mirror, $53 \%$ to the left-side mirror and only $30 \%$ to the left blind spot. These values were all greater than for straight-ahead driving, for which most of the glances were directed toward the rear-view mirror or the instrument cluster (23\% and $25 \%$, respectively) with almost no glances toward the left-side mirror (10\%) and the left blind spot (3\%).

Despite the importance of these perceptual-motor processes, there is a scarcity of information about the specific effect of aging on eye-head movements during lane-change manoeuvres. The aim of the present study was to examine, before a left-lane change, whether or not older drivers sample their mirrors (rear-view and left-side) and the left blind spot less frequently than young and active drivers. For this purpose, we tested young and older active drivers in a simulated environment with identical controlled driving contexts.

\section{METHODS}

\section{Subjects}

Twelve young (age range $=20-24$ years) and eleven older (age range $=66-75$ years) active drivers took part in the study. Upon their arrival in the laboratory, each participant was briefed on the requirements of the experiment and all read and signed an informed consent that conformed to the Laval University Institutional Review Board requirements. Then, subjects were given a general verbal questionnaire that included items on driving (years of driving experience, frequency of driving and average $\mathrm{km} / \mathrm{year}$, number of accidents within the last years) and general health condition (neurological and musculoskeletal problems, use of medication). Simple clinical tests (MMSE, Snellen visual acuity, Melbourne Edge test, ankle proprioception acuity, lower limb touch thresholds measured with a Semmes-Weinstein pressure aesthesiomether) were used to screen for impairments that might affect driving and cognition. All elderly subjects scored 27 or higher on the MMSE and had normal or corrected to normal vision. They also reported having driven more than $5000 \mathrm{~km}$ in the preceding year. Table 1 provides a summary of these results.

\section{Apparatus and Procedures}

The experiment was conducted with a fixed-based open-cab simulator powered by STISIM Drive 2.0 (Allen et al., 1997). The simulator projects images on a flat wall $(1.45 \mathrm{~m}$ high x $2.0 \mathrm{~m}$ 
wide) located $2.2 \mathrm{~m}$ from the steering wheel using a LCD projector (Hitachi CP-X275). It displays a $40^{\circ}$ horizontal by $30^{\circ}$ vertical field-of-view with the center of the screen located at eye-level through the midline of the subject. To simulate real driving conditions, the left-side mirror and a panel positioned in the left blind spot are instrumented with a green and a red lightemitting diode (LED). The green LEDs inform the driver that a lane change is possible, whereas the red LEDs instruct the driver to continue driving until green LEDs become active. The information displayed by the LEDs is in correspondence with the information displayed in the rear-view mirror. To capture visual information during lane changes, three IEEE-1394 video cameras (Prosilica CV-640) were mounted on the cab facing the subject and zoomed to fully capture head and eye movements. None of the cameras interfered with the visual field. To maintain ideal lighting conditions for the simulation, infrared lighting was provided with three illuminators (Cantronic $30 \mathrm{deg}$ with $850 \mathrm{~nm}$ wave length). Head movements (panning) were recorded with an electromagnetic system (Flock of Birds) fixed on a small headband. A fourth camera (Point Grey Research, Flea BW) captured the scenario displayed on the screen. Data acquisition was time-locked with hardware signals and collected on three different computers (all DV signals collected at $30 \mathrm{~Hz}$ with custom software developed using Unibrain Fire-API SDK; head movements recorded at $60 \mathrm{~Hz}$ using ASL software; car and steering responses recorded with STISIM software). Data were collected for specific events during an overall scenario (see below).

Table 1. Summary of results for the general health evaluation and driving experience

\begin{tabular}{|c|c|c|c|}
\hline mean values (standard deviations) & Young drivers & Elderly drivers & P values \\
\hline Age & $21.2(1.55)$ & $69.25(3.07)$ & $<0.01$ \\
\hline Years of experience & $4.1(2.2)$ & $45.1(10.0)$ & $<0.01$ \\
\hline Kilometers per year & $6760(3288)$ & $9683(4146)$ & $>0.05$ \\
\hline Accident within the last years & $0.6(0.8)$ & $0.7(0.7)$ & $>0.05$ \\
\hline MMSE & $28.50(0.07)$ & $27.50(0.67)$ & $<0.01$ \\
\hline Snellen visual acuity High contrast & $0.82(0.33)$ & $0.9(0.13)$ & $>0.05$ \\
\hline Snellen visual acuity Low contrast & $1.24(0.56)$ & $1.48(0.28)$ & $>0.05$ \\
\hline Melbourne edge test & $22.77(1.20)$ & $19.9(1.56)$ & $<0.01$ \\
\hline Ankle proprioception acuity (mean of 5 trials) & $1.08(0.69)$ & $2.4(10.2)$ & $<0.01$ \\
\hline Lower limb touch thresholds & $3.87(0.23)$ & $4.23(0.33)$ & $>0.05$ \\
\hline
\end{tabular}

Subjects were first familiarized with the simulator (Lavallière, Tremblay, Cantin, Simoneau, \& Teasdale, 2007) before driving through an uninterrupted driving scenario (26.4-km). Briefly, subjects were informed that the simulator could make them feel uncomfortable and they were specifically instructed to inform the experimenter if this happened. They were told the experiment would stop immediately without any prejudice toward them. To prevent uncomfortable sensations, the temperature within the room was maintained at about $17^{\circ} \mathrm{C}$ with proper ventilation using a ceiling vent positioned just above the driver. A $12-\mathrm{km}$ practice scenario (with less graphical information than the experimental scenario) served the purpose of familiarizing subjects with the simulator and the general feel of the pedals and steering. A 5-min rest between the practice and the experimental run was provided. With these measures, less than $5 \%$ of our subjects have ever reported sensations preventing them from pursuing the experiment. In the present study, all but 2 of the subjects reported being comfortable after the practice run. Data for these two subjects are not reported here. 
The scenario included 16 events for which the driver needed to look at the rear-view and left-side mirrors and at the left blind spot before a lane change. The lane changing maneuvers were necessary for 1) avoiding a static object partially or completely blocking the lane (e.g., a motionless car parked halfway into the shoulder, $n=7$ ), or 2) overtaking slower moving vehicles $(n=9)$. No emergency braking response was necessary unless a driving error was made. Subjects were asked to follow speed limits and to comply with local traffic regulation throughout the duration of the scenario. Schematic representations of two typical events are presented in Figure 1. The left panel illustrates a context where the driver (darker car) is on a 2-way road and approaching a police vehicle parked on the side of the road behind two other vehicles. An officer stands next to the car. On average, when engaging the lane change, the speed varied from 12 to $19 \mathrm{~km} / \mathrm{h}$ for all but one older driver, who nearly stopped before changing lanes. The right panel illustrates an event requiring overtaking a slower vehicle. The driver (darker car) is on a 2-way road approaching a slower moving vehicle. A car is approaching in the opposite lane. A solid line separates the 2-way road because of a wide curve towards the left. For all drivers, the speed varied from 45 to $52 \mathrm{~km} / \mathrm{h}$ before overtaking the slower vehicle.

Overall, we analyzed 173 events for the young subjects (78 events with a partial lane change and 95 events with a complete lane change) and 153 events for the elderly (69 and 84 events, respectively). Video streams of the head and the screen were observed simultaneously frame by frame with head movements and car data. Frequency of glance responses to each of the three ROIs (rear-view mirror, left-side mirror, blind spot) was measured. Mean frequency to each ROI were calculated for all drivers. Data were submitted to a Group (Young, Elderly) x Driving maneuvers (avoiding static object, overtaking slower vehicle) x ROI (rear-view mirror, left-side mirror, blind spot) with repeated measures on the last two factors.

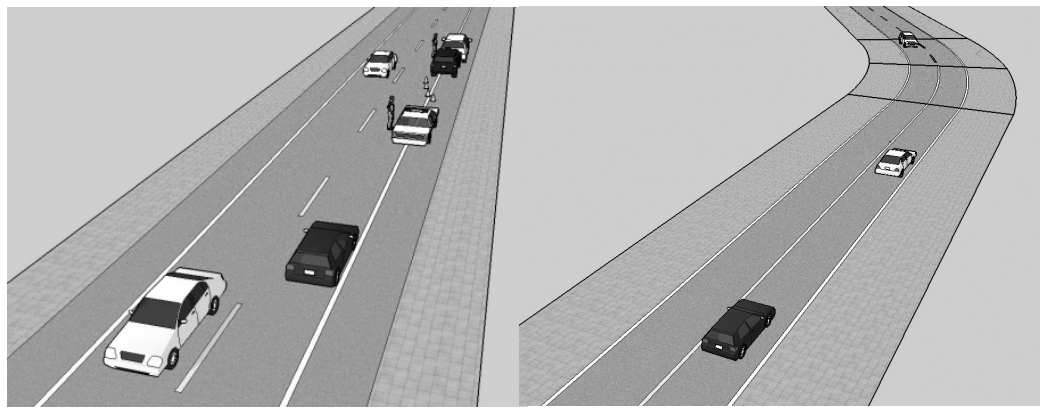

Figure 1. Schematic representations of events where avoiding a static object (left panel) and a complete lane change for overtaking a slower moving car (right panel) were necessary.

\section{RESULTS}

The main goal of this study was to document whether active elderly drivers, when they changed lanes, visually sampled the environment (rear-view mirror, left-side mirror and blind spot) as often as younger active drivers. Figure 2 presents the frequency of eye glances to the three different ROI for the avoiding and overtaking maneuvers (data for the young and elderly drivers when changing lanes to avoid a static object or to overtake a slower vehicle are presented). The ANOVA yielded main effects of Group $(\mathrm{F}(1,21)=16.34, \mathrm{p}<0.001)$ and Maneuvers $(\mathrm{F}(1,21)=27.47, \mathrm{p}<0.001)$, as well as two-way interactions for Group x ROI $(\mathrm{F}(2,42)=4.46$, 
$\mathrm{p}<0.05)$ and Group x Maneuvers $(\mathrm{F}(1,21)=17.44, \mathrm{p}<0.001)$. All other effects were not significant $(\mathrm{p}>0.05)$. A decomposition of the Group $x$ ROI interaction indicates that, on average, older drivers sampled their rear-view mirror and blind spot less frequently than younger drivers $(51 \%$ vs. $80 \%$ for the rear-view mirror; $40 \%$ vs. $86 \%$ for the blind spot). No difference was observed in the sampling frequency of the left-side mirror (73\% vs. 76\%). The Group x Maneuvers interaction indicates that while older drivers showed a constant glance frequency for both driving contexts (53\% vs. 56\% for the avoiding and overtaking maneuvers, respectively), younger drivers increased considerably their sampling of the environment for all ROI when overtaking a slower vehicle (70\% vs. $92 \%$, respectively).

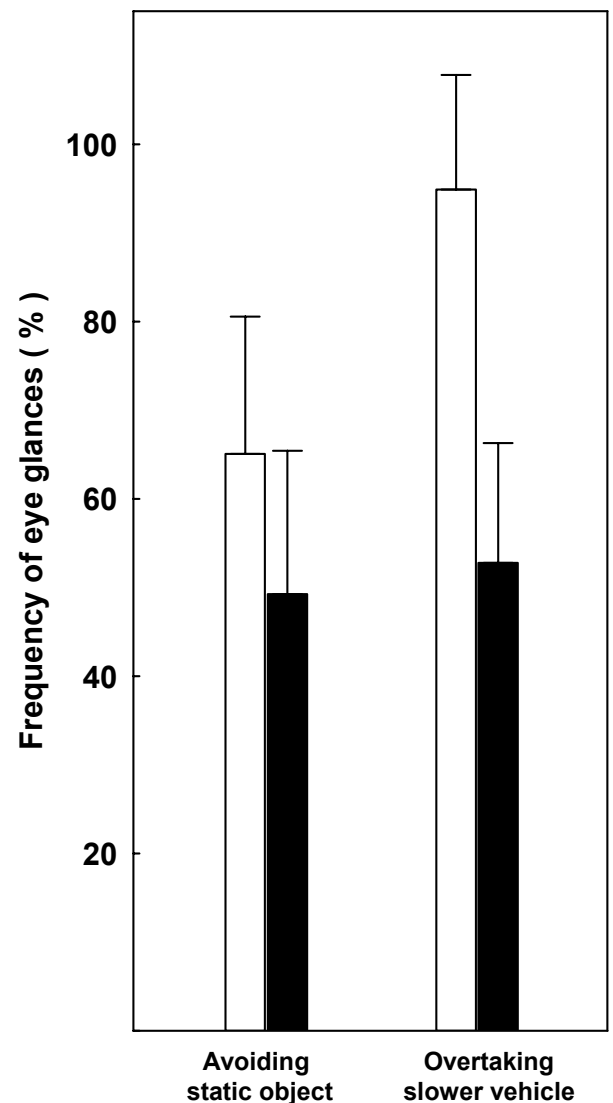

Rear view mirror

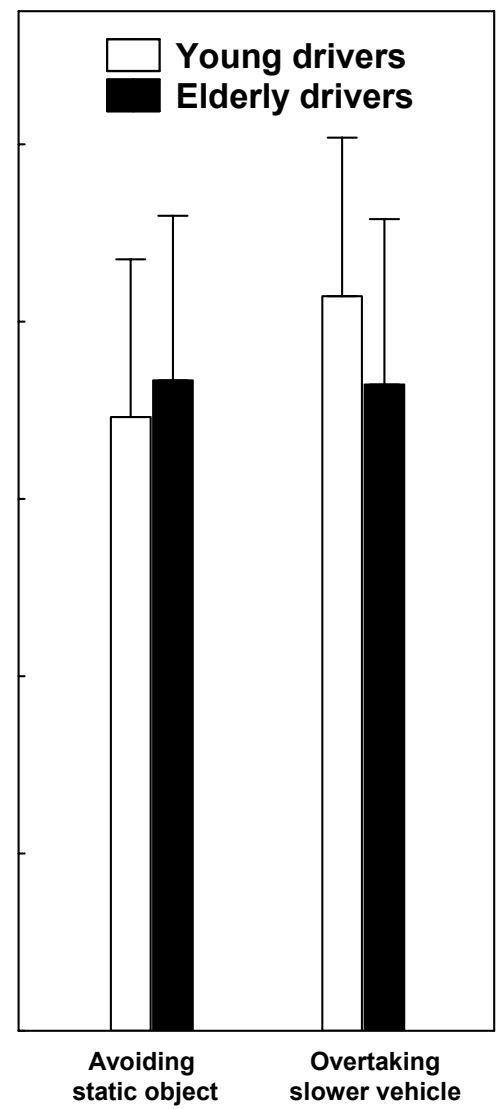

Left side mirror

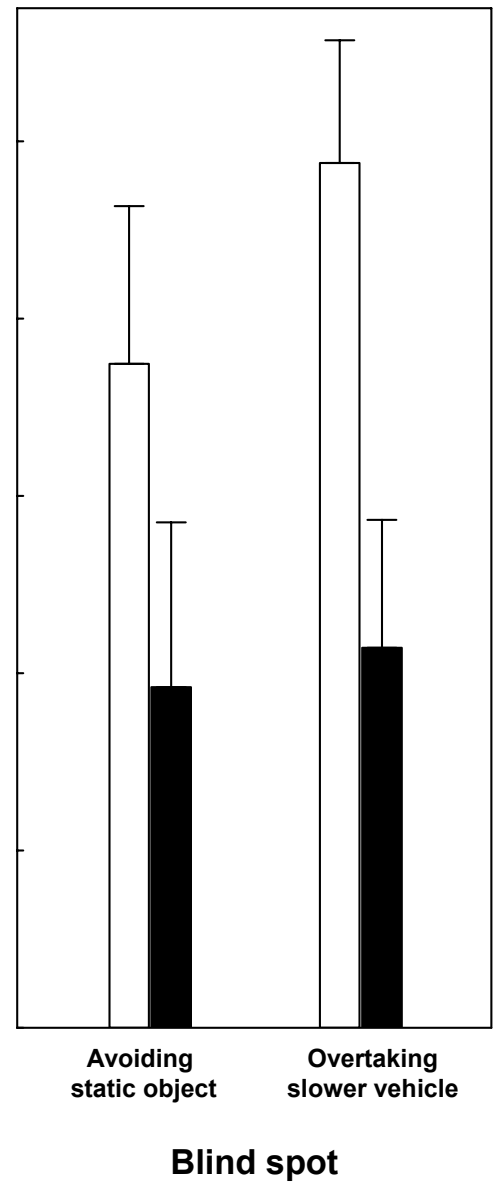

Blind spot

Figure 2. Mean frequency of eye glances to the rear-view and left-side mirrors and the blind spot. Error bars indicate the between-subjects $95 \%$ confidence interval.

\section{DISCUSSION}

The present study shows that, before a lane change, elderly drivers did not glance at three important ROI (rear-view and left-side mirrors and blind spot) as often as their younger counterparts. This was particularly apparent for the rear-view mirror and the blind spot. Also, and contrary to younger drivers, they adopted a more stereotypical glance behaviour that did not vary with the driving context. Younger drivers showed an increased frequency of glances towards the rear-view mirror and the blind spot when overtaking a slower vehicle (presumably a more complex manoeuvre performed at a higher speed than avoiding a static object). Compared 
to recent values obtained with on-the-road testing (Olsen et al., 2002; 2005), the frequency of glances we are reporting look inflated. Indeed, Olsen and colleagues reported that $46 \%$ of the left-lane changes had a glance to the rear-view mirror, $53 \%$ to the left-side mirror and only $30 \%$ to the left blind spot. A major discrepancy with our experiment (beyond the fact that our experiment was conducted with a simulator, whereas that of Olsen et al. was on-the-road) is that we coded glances for a 15-s period preceding the onset of the lane change, whereas Olsen and colleagues limited their analysis to a 3-s period.

We believe these findings are important as they suggest that elderly drivers may exhibit some visual search deficits. For instance, when driving on a monotonous road, there are reports of a perceptual narrowing for older drivers (Roge et al., 2004). Also, older drivers are less accurate, especially with high-clutter scenes, and slower to identify the information available in a scene (Maltz \& Shinar, 1999; McPhee, Scialfa, Dennis, Ho, \& Caird, 2004). Such behaviours could put them at risk when changing lanes. Also, elderly drivers are particularly inefficient at monitoring their own performance (Freund, Colgrove, Burke, \& McLeod, 2005; Holland \& Rabbit, 1994). Although they are aware of what hazardous situations consist of, they seem unable to realize that some of these situations may be dangerous for them. Such an attitude (i.e., high self-rating even in the presence of declining skills) is an obstacle to self-modification of driving habits since an essential aspect of learning consists in evaluating one's errors (Salmoni, Schmidt, \& Walter, 1984).

In the present study, the scenario did not include emergency contexts or risky situations. Nevertheless, some of the elderly drivers' behaviors lead to such risky situations (e.g., lane change that were not preceded by specific glances to the blind spot or the left-side mirror although a vehicle was approaching; this led to an accident in one case). Recent work by Romoser et al. (Romoser, Fisher, Mourant, Wachtel, \& Sizov, 2005) is of utmost importance with regard to the possibility of training older drivers. Using a driving simulator and eye movement recording devices, they reported having achieved increased drivers' situational awareness through one-on-one post-training debriefing and feedback. For instance, in the context of reaching an intersection, the provided feedback mostly focused on advising the driver to take more primary and secondary glances toward oncoming traffic primarily through extra head movements. Six months following this one-on-one feedback session, drivers (young and old) were re-tested to check whether or not they had integrated the information learned during the training program. Both young and old drivers reduced their error rate (e.g., failure to glance into adjacent line before merging) by $12.5 \%$. Similarly, Pradhan et al. (2005) reported significant improvement in recognizing high-risk situations using a driving simulator for training drivers in increasingly active eye movements. To our knowledge, these two experiments are the first attempts at reinforcing behaviours associated with skilled driving (for a discussion of the positive effect of error training in a simulator vs. guided learning, see Ivancic and Hesketh 2000). This suggests that in-simulator training could be an important method for modifying and reinforcing proper driving behaviours. While on-road assessment of driver training is still considered the reference, driving simulators could offer an efficient, cost-effective and safe means of retraining older drivers. 


\section{ACKNOWLEDGMENTS}

Special thanks to all drivers that participated in the project. This project (COBVIS-D) received support from AUTO21 and the Société de l'Assurance Automobile du Québec (SAAQ).

\section{REFERENCES}

Allen, R.W., Rosenthal, T.J., Aponso, B.L., Klyde, D.H., Anderson, F.G., Hogue, J.R., et al. (1997). A Low Cost PC Based Driving Simulator for Prototyping and Hardware-In-TheLoop Applications, SAE International Congress \& Exposition.

Cooper, P.J. (1990). Differences in accident characteristics among elderly drivers and between elderly and middle-aged drivers. Accident Analysis and Prevention, 22(5), 499-508.

Crundall, D., \& Underwood, G. (1998). The effects of experience and processing demands on visual information acquisition in drivers. Ergonomics, 41, 448-458.

Falkmer, T., \& Gregersen, N. P. (2005). A comparison of eye movement behavior of inexperienced and experienced drivers in real traffic environments. Optometry and Vision Science, 82(8), 732-739.

Freund, B., Colgrove, L., Burke, B., \& McLeod, R. (2005). Self-rated driving performance among elderly drivers referred for driving evaluation. Accident Analysis and Prevention, 37(4), 613-618.

Holland, C.A., \& Rabbit, P.M.A. (1994). The problems of being an older driver: comparing the perceptions of an expert group and older drivers. Applied Ergonomics, 25(1), 17-27.

Ivancic, K., \& Hesketh, B. (2000). Learning from errors in a driving simulation: effects on driving skill and self-confidence. Ergonomics, 43(12), 1966-1984.

Keskinen, E., Ota, H., \& Katila, A. (1998). Older drivers fail in intersections: speed discrepancies between older and younger male drivers. Accident Analysis and Prevention, 30(3), 323-330.

Land, M.F. (2006). Eye movements and the control of actions in everyday life. Progress in Retinal and Eye Research, 25(3), 296-324.

Lavallière, M., Tremblay, M., Cantin, V., Simoneau, M., \& Teasdale, N. (In press). Aging yields a smaller number of fixations and a reduced gaze amplitude when driving in a simulator. Advances in Transportation Studies: An International Journal, Special issue.

Maltz, M., \& Shinar, B. (1999). Eye movements of younger and older drivers. Human Factors, 41(1), 15-25.

McPhee, L.C., Scialfa, C.T., Dennis, W.M., Ho, G., \& Caird, J.K. (2004). Age differences in visual search for traffic signs during a simulated conversation. Human Factors, 46(4), 674685.

Mourant, R. R., \& Rockwell, T. H. (1972). Strategies of visual search by novice and experienced drivers. Human Factors, 14, 325-335. 
Olsen, E. C. B., Lee, S. E., \& Wierwille, W. W. (2002). Analysis of distribution, frequency, and duration of naturalistic lane changes. Proceeding of the Human Factors and Ergonomics Society 46th Annual Meeting, 1789-1793.

Olsen, E. C. B., Lee, S. E., \& Wierwille, W. W. (2005). Eye glance behavior during lane changes and straight-ahead driving. Transportation Research Board Meeting.

Owsley, C., Ball, K., McGwin, G., Jr., Sloane, M. E., Roenker, D. L., White, M. F., et al. (1998). Visual processing impairment and risk of motor vehicle crash among older adults. Journal of the American Medical Association, 279(14), 1083-1088.

Pradhan, A. K., Hammel, K. R., DeRamus, R., Pollatsek, A., Noyce, D. A., \& Fisher, D. L. (2005). Using eye movements to evaluate effects of driver age on risk perception in a driving simulator. Human factors, 47(4), 840-852.

Robinson, G. H., Erickson, D. J., Thurston, G. L., \& Clark, R. L. (1972). Visual search by automobile drivers. Human Factors, 14(4), 315-323.

Roge, J., Pebayle, T., Lambilliotte, E., Spitzenstetter, F., Giselbrecht, D., \& Muzet, A. (2004). Influence of age, speed and duration of monotonous driving task in traffic on the driver's useful visual field. Vision Research, 44(23), 2737-2744.

Romoser, M. R. E., Fisher, D. L., Mourant, R. R., Wachtel, J., \& Sizov, K. (2005). The use of a driving simulator to asses senior driver performance: increasing situational awareness through post-drive one-on-one advisement. Paper presented at the Proceeding of the Third International Driving Symposium on Human Factors in driver Assesment, Training and Vehicle Design.

Salmoni, A. W., Schmidt, R. A., \& Walter, C. B. (1984). Knowledge of results and motor learning: A review and critical reappraisal. Psychological Bulletin, 95, 355-386.

Underwood, G., Chapman, P., Brocklehurst, N., Underwood, J., \& Crundall, D. (2003). Visual attention while driving: sequences of eye fixations made by experienced and novice drivers. Ergonomics, 46(6), 629-646.

Underwood, G., Crundall, D., \& Chapman, P. (2002). Selective searching while driving: the role of experience in hazard detection and general surveillance. Ergonomics, 45(1), 1-12. 